\title{
PENGEMBANGAN INSTRUMEN TES HIGHER ORDER THINKING SKILL (HOTS) PADA POKOK BAHASAN SISTEM PERSAMAAN LINEAR DUA VARIABEL DAN TEOREMA PYTHAGORAS
}

\section{DEVELOPING HIGHER ORDER THINKING SKILL (HOTS) TEST INSTRUMENT ON LINEAR EQUATION SYSTEM WITH TWO VARIABLES AND PYTHAGOREAN THEOREM}

\author{
Martina1), Misykat Malik Ibrahim²), Andi Kusumayanti3), Nursalam4) \\ 1,2,3,4)Fakultas Tarbiyah dan Keguruan Universitas Islam Negeri Alauddin Makassar \\ martina@gmail.com ${ }^{1)}$, mikka97@yahoo.com ${ }^{2}$, andi.kusumayanti@uin-alauddin.ac.id ${ }^{3}$ ) \\ nursalam ftk@uin-alauddin.ac.id ${ }^{4}$ )
}

\begin{abstract}
Abstrak
Penelitian ini bertujuan untuk mengembangkan instrumen tes berstandar HOTS dalam bentuk uraian sesuai kriteria validitas, daya pembeda, tingkat kesukaran, serta reliabilitas. Penelitian ini masuk dalam jenis penelitian dan pengembangan. Prosedur yang digunakan ialah desain formatif dari tessmer yang terdiri dari preliminary, self evaluation, prototyping, and field test. Subyek yang dipilih ialah siswa dari kelas VIII SMP Citra Samata. Data-data dikumpulkan melalui tes, sedangkan instrumen yang digunakan berupa lembar tes dan validasi. Instrumen yang digunakan masuk ke kategori valid yaitu $V a$ 4,13. Reliabilitas yang didapatkan yaitu 0,69 dengan ketegori tinggi. Berdasarkan kriteria kualitas instrumen tes diketahui bahwa terdapat 10 soal mempunyai daya pembeda yang memenuhi kriteria sedangkan 5 soal tidak memenuhi daya pembeda.
\end{abstract}

Kata Kunci: Higher Order Thinking Skill (HOTS), instrumen tes, sistem persamaan linear dua variabel, teorema pythagoras

\begin{abstract}
This study aims to develop a HOTS standardized test instrument in the form of a description according to the criteria for validity, differentiation, difficulty level, and reliability. This research is included in the type of research and development. The procedure used is a Tessmer formative design consisting of preliminary, self-evaluation, prototyping, and field tests. The subjects chosen were students from class VIII SMP Citra Samata. The data were collected through tests, while the instruments used were test and validation sheets. The instrument used was included in the valid category, namely Va 4.13. The reliability obtained is 0.69 with high category. Based on the quality criteria of the test instrument, it is known that there are 10 questions that have discriminatory power that meet the criteria while 5 questions do not meet the discriminatory power.
\end{abstract}

Keywords: Higher Order Thinking Skill (HOTS), test instrument, linear equations system with two variables, the Pythagorean theorem

How to Cite: Martina, Ibrahim, M. M., Kusumayanti, A., Nursalam. (2021). Pengembangan instrumen tes Higher Order Thinking Skill (HOTS) pada pokok bahasan sistem persamaan linear dua variabel dan teorema pythagoras. Al asma: Journal of Islamic Education, 3(1), 85-96. 


\section{PENDAHULUAN}

Pendidikan mempunyai peran yang sangat penting pada kelangsungan hidup seseorang karena fitrahnya manusia lahir tidak berilmu. Oleh sebab itu manusia perlu pendidikan di sepanjang hidupnya hingga mendapatkan kemajuan dan kesejahteraan. Dengan pendidikan, kita bisa melihat sejauh mana suatu bangsa bisa bersaing. Begitu pun dengan proses pendidikan yang hasilnya belum optimal di Indonesia, karenanya diperlukan upaya dengan mengadakan evaluasi ulang terhadap kegiatan pendidikan agar bisa bersaing. Pendidikan mengandung beberapa komponen bidang pelajaran yang harus dikuasai siswa sebagai dasar untuk menjadikannya pribadi yang berkompetensi, tanggap dan siap diberbagai situasi yang dihadapinya dimasa depan, dan matematika adalah salah satu komponen bidang yang harus dikuasai siswa (Saraswati, Suharta, \& Pujawan, 2020). Matematika menjadi pendidikan yang paling esensial dari banyaknya cabang ilmu dan digolongkan dalam deretan mata pelajaran wajib di sekolah (Nur, 2017).

Di antara komponen paling berharga saat pelaksanaan pendidikan ialah penilaian. Perubahan kualitas pendidikan menjadi lebih baik bisa dilakukan melalui perubahan kualitas pembelajaran dan sistem penilaian yang lebih baik (Ndiung \& Mariana Jediut, 2020). Penilaian pada hasil belajar seseorang dilaksanakan dengan banyak teknik yang valid terhadap kompetensi penilaian (Subagia \& Wiratma, 2016). Teknik penilaiannya ialah: 1) penilaian komptensi pada sikap dengan pengamatan, penilaian diri dan teman sejawat, dan jurnal; 2) penilaian kompetensi pengetahuan dengan tes baik tertulis atau lisan, dan penguasaan; 3) penilaian kompetensi pada keterampilan dengan tes, projek, serta portofolio (Setiadi, 2016).

Tingkat suatu tes dikatakan baik dilihat dari kepiawaiannya memberi gambaran yang jelas tingkatan keberhasilan programnya atau tujuan pembelajarannya. Agar tujuan mudah dinilai keberhasilannya, maka tujuan itu harus operasional dan terklasifikasikan dengan rinci. Taksonomi yang digunakan dalam pendidikan untuk mengklasifikasi tujuan instruksional dibagi dalam 3 domain, yakni ranah pengetahuan yang berhubungan dengan tujuan orientasi belajar, 2) ranah afektif yang berhubungan pada perasaan, sikap hati, dan emosi, 3) ranah psikomotor yang berhubungan dengan kepiawaian motorik (Netriwati, 2018). Benjamin. S. Bloom membentuk kelompok sesuai urutan keterampilan berpikir pada proses yang semakin tinggi seiring dengan lamanya proses tersebut (Effendi, 2017).

Taksonomi bloom revisi pada ranah pengetahuan memuat 6 kategori utama yang jika diurutkan dari tingkatan paling rendah ke tinggi, yaitu mengingat, memahami, mengaplikasikan, menganalisis, mengevaluasi, dan mencipta. (Gunawan \& Palupi, 2016). Soal kategori mudah dikembangkan dengan kemampuan pengetahuan dan pemahaman, soal kategori sedang dikembangkan dengan kemampuan penerapan dan analisis, sedangkan soal kategori sukar dikembangkan dengan kemampuan sintesis dan evaluasi (Erniyanti, Junus, \& Syam, 2020).

SMP Citra Samata merupakan sekolah swasta yang ada di Kabupaten Gowa. Dari studi terdahulu melalui observasi dan wawancara diketahui bahwa hasil belajar matematika siswa belum bisa memuaskan bahkan banyak siswa yang remedial. Faktornya bisa jadi karena instrumen tes hanya menguji pengetahuan, pemahaman yang menilai 
kemampuan berpikir tingkat rendah, serta penerapan. Padahal di dalam buku yang sudah mengacu dengan kurikulum 2013 sudah tertuang beberapa soal yang menilai kemampuan tingkat tinggi. Jadi di sini guru kurang mengembangkan instrumen tes, belum ada yang dirancang khusus melatih HOTS, sehingga para siswa kurang latihan mengerjakan soal yang menilai kemampuan tingkat tinggi.

Tes menjadi alat ukur mengumpulkan data dan merupakan rangkaian latihan yang mengukur kepiawaian intelegensi, pengetahuan, dan motorik yang dimiliki individua tau pun kelompok (Sridadi \& Utama, 2016). Saat membuat soal, dibutuhkan indikator di mana guru harus beradaptasi dengan buku panduan dalam pembelajaran (Nurfillaili, Yusuf, \& Anggereni, 2016). Kemampuan siswa dibatasi beberapa contoh soal dari guru. Siswa akan merasa bahnwa soal akan mudah dikerjakan jika soal yang diberikan sama dengan contoh yang sudah dijelaskan oleh guru dan akan merasa bahwa soal tersebut sulit jika soal yang diberikan tidak sama dengan contoh yang diberikan (Afirda, Sa'o, \& Dhiki, 2020). Hal ini kemudian menjadi masalah yang dianggap sebagai penyebab prestasi belajar siswa menjadi rendah.

Berdasarkan ketidaksesuaian antara kejadian semestinya dengan yang terjadi di lapangan yang ada kaitannya dengan tes, kepiawaian berpikir dan alat ukur yang digunakan. Maka solusinya ialah dengan membiasakan para siswa mengembangkan kemampuan berpikirnya sesuai potensi diri masing-masing, yakni dengan mengembangkan assesmen yang membiasakan untuk berpikir tingkat tinggi bukan sekedar menghafal rumus untuk menyelesaikan soal. Hal ini akan memudahkan siswa untuk memecahkan permasalahan dan kemampuan berpikir tingkat tinggi akan meningkat serta hasil belajar mereka akan memuaskan. Membiasakan mengerjakan soal yang setara PISA atau HOTS akan mewujudkan harapan untuk bisa bersaing dengan negara lain. Penelitin Tri Atika Okta, dengan judul "Pengembangan Soal-Soal Sistem Persamaan Linear Satu Variabel berbasis Higher Order Thinking Skills" menyimpulkan bahwa soal yang dihasilkan sudah mencapai kategori yang sangat reliabel juga valid, serta hasil tanggapan siswa didapatkan nilai rerata 3,2, sehingga praktis untuk digunakan dalam pembelajaran (Okta, 2020). Hasil penelitian Riza Yonisa Kurniawan dan Dian Lestari dengan judul "The Development Assessment Instrumens of Higher Order Thinking Skills on Economic Subject" juga menunjukkan bahwa instrumen penilaian valid dan reliabel dan soal telah memenuhi kriteria kualitas soal berbasis HOTS, serta secara keseluruhan para siswa rata-rata mempunyai kemampuan berpikir yang tinggi dengan kategori cukup (Kurniawan \& Lestari, 2019), sedangkan hasil penelitian oleh Syukrul Hamdi dkk dengan judul "Developing Higher Order Thinking Skill (HOTS) Tes Instrumen Using Lombok Local Cultures as Contexts for Junior Secondary School Mathematics" menyimpulkan bahwa validitas tes yang ditunjukkan oleh penilaian para ahli menunjukkan bahwa tes tersebut baik untuk digunakan pada aspek isi, format, dan bahasa, serta instrumen memenuhi syarat reliabilitas dengan kategori baik dan tingkat kesukaran dengan kategori sedang (Hamdi, Suganda, \& Hayati, 2018). Alasan-alasan di atas yang menjadi motivasi peneliti untuk meneliti kasus ini. 


\section{METODE PENELITIAN}

Penelitian yang diselenggarakan termasuk penelitian pengembangan atau dikenal dengan R \& D. Tahapan pelaksanaan mengacu pada sintaks model pengembangan formative research tessmer (1993).
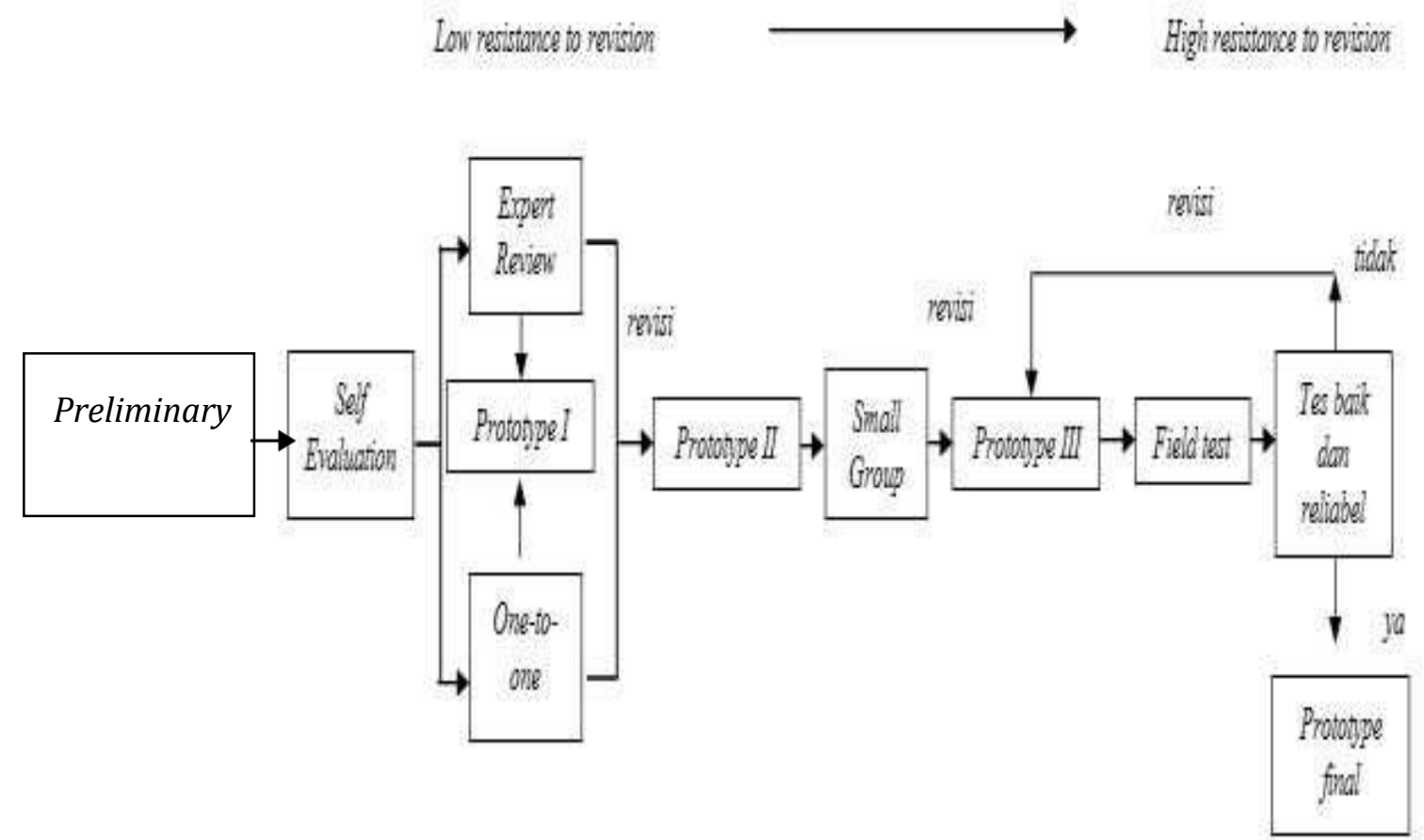

Gambar 1. Diagram Alur Pengembangan Instrumen Tes Model Tessmer

Berdasarkan gambar di atas, terdapat 2 tahapan garis besar dalam alur penelitian ini, yakni tahap pleminary, tahap self evaluation, tahap prototyping, serta tahap field tes yang dijabarkan berikut ini:

1. Tahap preliminary, sebagai langkah awal pada penelitian ini. Peneliti mengawali tahapan penelitian dengan menganalisis tempat serta subyek yang ingin dipilih.

2. Tahap self evaluation, tahap ini memuat analisis dan rancangan.

3. Tahap prototyping, tahap ini memuat exper review, one to one, serta small group.

4. Tahap field test, tahap ini memuat perbaikan dari uji coba pada subyek penelitian. 


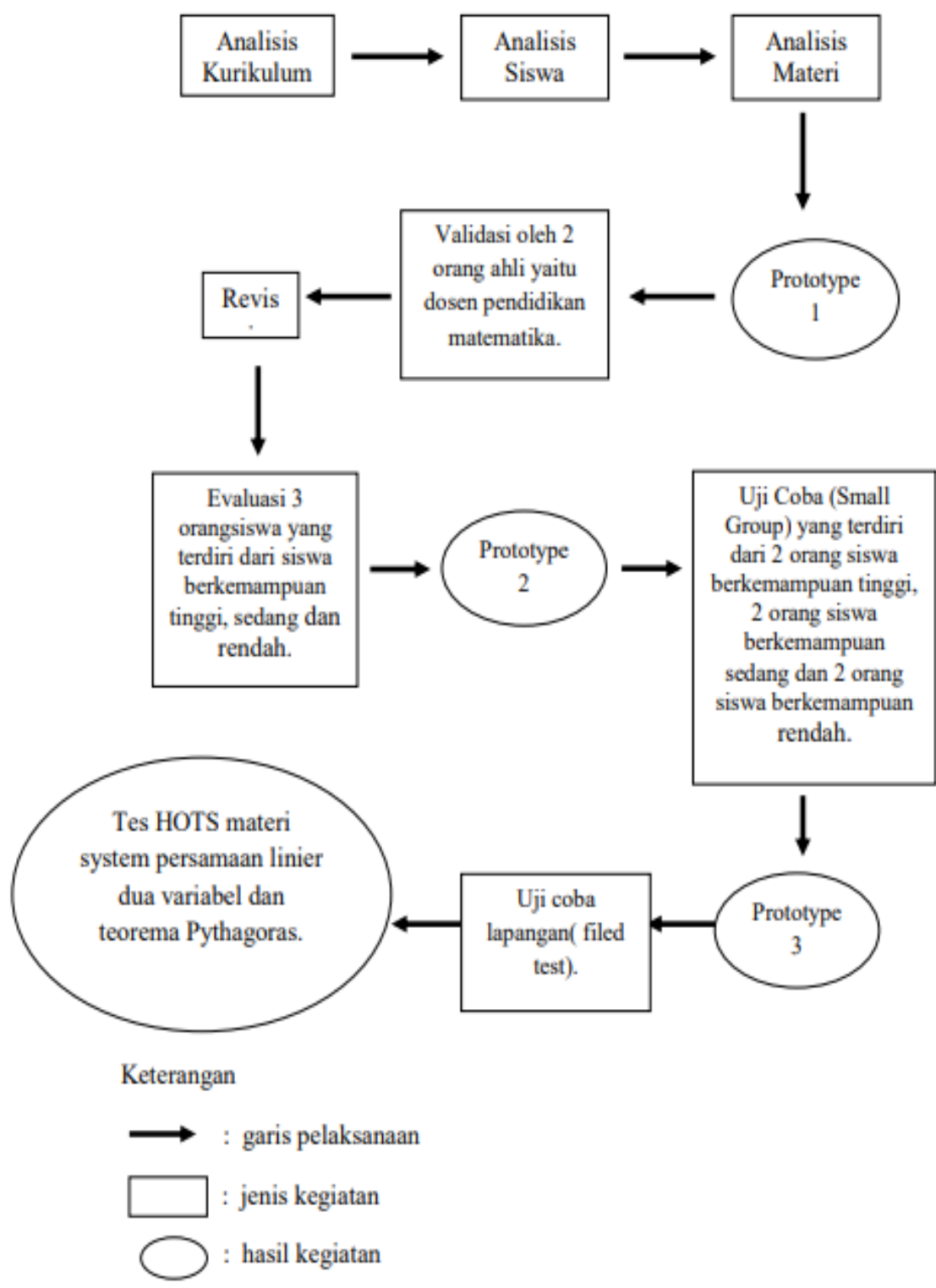

Gambar 2. Alur Pengembangan Tes HOTS

Siswa dari kelas VIII di SMP Citra Samata dipilih menjadi subjek penelitian. Alat ukur penelitian (instrumen) berupa lembar tes dan validasi. Pengkategorian keterampilan berpikir di tingkat tinggi sudah ditentukan seperti tabel berikut (Faisal, 2015):

Tabel 1. Kategori Level Kemampuan Berpikir Tingkat Tinggi

\begin{tabular}{cc}
\hline Nilai Siswa & Level Kemampuan Berpikir \\
\hline $80<$ nilai $\leq 100$ & Sangat baik \\
$60<$ nilai $\leq 80$ & Baik \\
$40<$ nilai $\leq 60$ & Cukup \\
$20<$ nilai $\leq 40$ & Kurang \\
$0<$ nilai $\leq 20$ & Sangat kurang \\
\hline
\end{tabular}




\section{HASIL DAN PEMBAHASAN}

Penelitian ini melalui rangkaian sintaks dari model pengembangan yang digunakan. Penjelasan dari setiap tahapan diuraikan sebagai berikut.

\section{Tahap Preliminary}

Tahap ini diawali pengumpulan berbagai referensi yang ada kaitannya dengan pengamatan ini. Referensi yang didapatkan memuat berbagai teori yang dikemukakan para ahli. Diantara teori yang dimaksud ialah dari Sumarno kemampuan memecahkan masalah memuat 4 indikator yakni memahami permasalahan, merencanakan pemecahan permasalahan, menyelesaikan permasalahan, serta memeriksa ulang penyelesaian yang sudah diselesaikan. Setelah tempat dan subyek uji coba ditentukan, maka pengamatan melalui wawancara dilakukan. Wawancara/interview dilakukan pada guru MTK yang mengajar dalam kelas VIII.

\section{Tahap Self Evaluation}

Tahapan ini bermaksud mendesain instrumen/alat ukur penelitian yang memuat kisi-kisi dan soal tes, jawaban, serta rubrik penskoran. Tahap ini dibagi dalam 2 tahapan yakni analisis dan desain. Tahap analisis terdiri dari analisis kurikulum, analisis siswa, dan analisis materi.

Pengembangan pada tes mengikut kurikulum 2013 yang didalamnya memuat tujuan meningkatkan kemampuan siswa memecahkan suatu permasalahan matematika (MTK). Proses pembelajarannya mengarah kepada karakteristik suatu kompetensi yang meliputi sikap, keterampilan, dan pengetahuan. Bukan hanya itu, kegiatan pembelajaran untuk kurikulum ini menggunakan saintifik yang bermaksud mengembangkan keterampilan intelek siswa terkhusus untuk aspek pemecahan masalah. Dari kegiatan wawancara diketahui penerapan kurikulum 2013 dimulai sejak pencanangan kurikulum ini oleh pemerintah. Oleh sebab itu materi yang sama dengan pembuatan instrumen tes diselaraskan dengan materi di kelas VIII dengan kurikulum 2013 yakni SPL dan teorema Pythagoras.

Kegiatan menganalisis dipusatkan kepada siswa yang menjadi subyek penelitian dalam hal ini kelas VIII karena sudah mempelajari materi tersebut. Ada 38 orang yang berada di kelas VIII. Dari kegiatan wawancara diketahui pula pengetahuan para siswa ada yang kurang, sedang, dan ada yang tinggi. Hal ini bisa terjadi karena perbedaan minat dari masing-masing siswa yang tidak sama. Umumnya kemampuan berpikir yang tinggi belum ada yang menelusuri, baik guru ataupun orang lain. Para siswa pun jarang mendapat soal yang sifatnya open problem solving yang bisa mengasah kemampuan berpikir seseorang.

Analisis pada materi merupakan aktivitas untuk mengidentifikasi berbagai konsep inti yang bisa digunakan Ketika membuat soal. Dari aktivitas menganalisis kurikulum diketahui bahwa pokok materi yang dipilih adalah sistem persamaan linear dan teorema pythagoras. Karenanya hal ini bisa dikembangkan indeks tiap soal yakni: 1) mengidentifikasi solusi suatu permasalahan yang berhubungan dengan SPLDV; 2) membuatkan model MTK serta menentukan solusi tentang SPLDV; 3) menyelesaikan permasalahan mengenai SPLDV dengan subtitusi; 4) menyelesaikan permasalahan mengenai SPLDV dengan eliminasi; 6) membuktikan tentang kebenaran dari teorema 
pythagoras serta triple pythagoras; 7) menyelesaikan permasalahan mengenai konsep dari teorema Pythagoras.

Selanjutnya ialah merancang instrumen tes yang berupa kisi-kisi dan tes soal, jawaban tes, serta rubrik penskoran. Awalnya peneliti merancang soal yang tingkatan berpikirnya tinggi. Setiap soal yang dirancang adalah bentuk uraian yang mempunyai kriteria sebagai pemecahan masalah matematika dengan kriteria analysis, evaluasi, juga mengkreasi. Tidak hanya itu, peneliti membuat kisi-kisi dari tes serta kriteria jawaban yang menjadi pertimbangan untuk validator memeriksa validitas soal-soal tes dengan keterampilan pemecahan masalah matematika. Selain itu peneliti juga merancang rubrik penskoran.

\section{Tahap Prototyping (Validasi, Evaluasi, dan Revisi)}

Target dari tahap ini ialah menghasilkan prototype kedua dari sebelumnya yang telah direvisi. Kegiatannya meliputi expert review, one to one, and small group. Kegiatan ini berupa validasi terhadap perangkat oleh tim ahli dengan perbaikan dan pengujian yang terbatas namun non subyek.

Expert review atau penilaian ahli berguna sebagai dasar untuk melakukan perbaikan dan pelengkapan prototipe. Validasi untuk instrumen dilakukan dengan memberikan lembar validasi dari setiap instrumen kepada validator. Validator akan menilai 10 item yang berhubungan dengan prototipe 2. Setiap item mempunyai nilai maksimal adalah 5 dan minimalnya adalah 1. Nilai 1 artinya tidak valid, 2 artinya kurang valid, 3 artinya cukup valid, 4 artinya valid, dan 5 artinya sangat valid. Semua validator memberi pendapat bahwa instrumen sudah baik dan bisa digunakan meski ada sedikit perbaikan. Di bawah ini merupakan saran dari validator.

Tabel 2. Revisi Prototype Berdasarakan Saran dan Masukan dari Validator

\begin{tabular}{|c|c|}
\hline $\begin{array}{c}\text { Prototype } \\
\text { yang } \\
\text { direvisi }\end{array}$ & Sebelum Revisi \\
\hline $\begin{array}{c}\text { Kisi-kisi } \\
\text { tes }\end{array}$ & 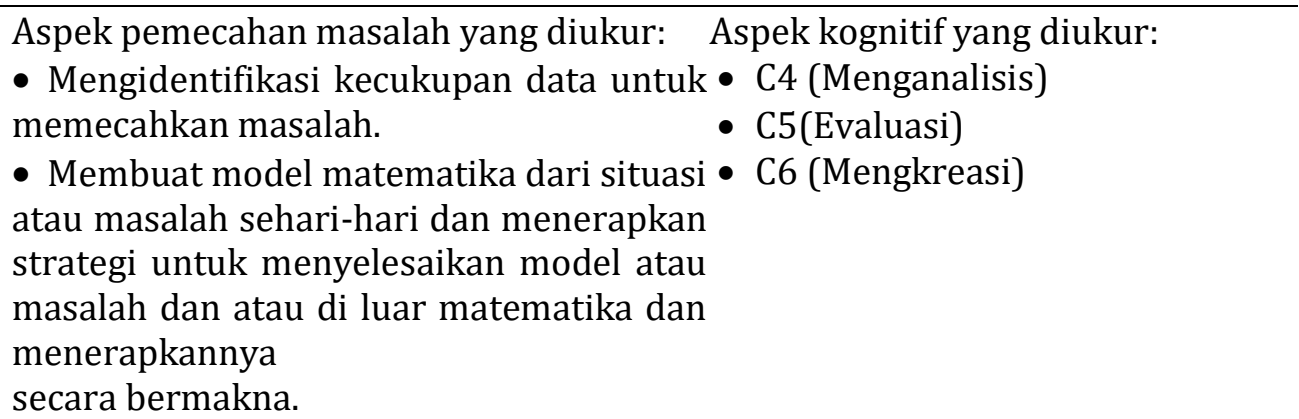 \\
\hline Soal Tes & $\begin{array}{l}\text { Soal sistem persamaan linear dua Risman memesan kursi dan meja } \\
\text { variabel: Risman memesan bangku pada seorang tukang kayu. Kursi } \\
\text { berkaki tiga dan meja berkaki empat pada yang dipesan empat buah lebih } \\
\text { seorang tukang kayu. Bangku yang banyak dari meja. Jumlah kaki } \\
\text { dipesan empat buah lebih banyak dari bangku dan meja yang digunakan } \\
\text { meja. Jumlah kaki bangku dan meja yang untuk memenuhi pesanan Risman } \\
\text { digunakan untuk memenuhi pesanan tersebut adalah } 68 \text { buah. Berapa } \\
\text { Risman tersebut adalah } 68 \text { buah. Berapa banyak kursi dan meja yang }\end{array}$ \\
\hline
\end{tabular}


banyak bangku berkaki tiga dan meja dipesan Risman?

berkaki empat yang dipesan Risman?

soal teorema pythagoras: Sebuah tangga Sebuah papan tripleks yang bersandar pada tembok yang tingginya 8 panjangnnya $8 \mathrm{~m}$ disandarkan $\mathrm{m}$. Jika kaki tangga terletak 6 meter dari pada dinding yang tingginya $4 \mathrm{~m}$ dinding, tentukanlah panjang tangga yang seperti tampak pada gambar. Jika bersandar pada tembok tersebut! kaki triplek itu terletak 3m dari dinding, hitunglah panjang tripleks yang menonjol di atas dinding!

Kunci Kunci jawaban mengenai soal.

jawaban Dik:keliling persegi panjang adalah $48 \mathrm{~m}$ panjangnya lebih $6 \mathrm{~m}$ dari lebarnya

Dit: Tentukan ukuran tanah itu?

Penyelesaian:

misal: panjang $=x$

lebar $=y$

keliling $=2$ (panjang + lebar)

$48=2(\mathrm{x}+\mathrm{y})$ atau $\mathrm{x}+\mathrm{y}=24 \ldots(1)$

$\mathrm{x}=\mathrm{y}+6$ atau $\mathrm{x}-\mathrm{y}=6 \ldots$ (2)

eliminasi persamaan (1) dan persamaan

(2)

$x+y=24$

$\underline{x-y}=6-$

$2 x=30$

$x=15$

subtitusikan

$x+y=24$

$15+y=24$

$y=24-15=9$

Jadi, ukuran tanah tersebut adalah $15 \mathrm{~m} \times$

$9 \mathrm{~m}$.

\section{Langkah 1 memahami masalah}

Dik: keliling persegi panjang adalah 48 meter panjangnya lebih

6 meter dari lebarnya

Dit: Tentukan ukuran tanah itu?

Penyelesaian:

Langkah 2 membuat rencana pemecahan masalah

misalkan: panjang $=x$

lebar $=y$

keliling = 2 (panjang + lebar)

$48=2(x+y)$ atau $x+y=24 \ldots(1)$

$\mathrm{x}=\mathrm{y}+6$ atau $\mathrm{x}-\mathrm{y}=6 \ldots$ (2)

Langkah 3 Melaksanakan rencana pemecahan masalah

eliminasi persamaan (1) dan persamaan (2)

$x+y=24$

$x-y=6-$

$2 x=30$

$x=15$

subtitusikan nilai $x=15$ ke persamaan $x+y=24$ diperoleh:

$x+y=24$

$15+y=24$

$y=24-15=9$

Langkah 4 Membuat

kesimpulan

Jadi, ukuran tanah tersebut adalah $15 \mathrm{~m} \times 9 \mathrm{~m}$.

Soal diuji coba secara one to one ke beberapa peserta didik, peserta didik tersebut yaitu tiga peserta didik sebaya nonsubjek dalam uji coba, dengan kemampuan rendah, sedang dan tinggi. Kategori tersebut didapatkan dari guru matematika kelas tersebut, dari kritik serta saran peserta didik, jadi instrumen bisa diteruskan dan menghasilkan prototype 2 . 
Komentar serta revisi exper review dan one to one menjadi dasar agar dapat menyususn soal untuk proses berikutnya dengan mengahasilkan prototype 2 yang akan diujocobakan dalam kelompok kecil nonsubjek, yaitu enam peserta didik. Berdasarkan masukan serta saran peserta didik, soal tersebut dilanjutkan ke fase uji coba lapangan (field tes).

\section{Tahap Field Test (Uji Coba Lapangan)}

Tes dilaksanakan dengan waktu 2 x 45 menit. Pencapaian yang didapatkan peserta didik digunakan untuk melihat tingkat pengusaan materi peserta didik. Selain dari hal tersebut hasil dari tes peserta didik juga akan dianlisis reliabilitas, daya pembeda instrumen, serta tingkat kesukan tes yang dikembangkan.

Berdasarkan pencapaian yang didapatkan pada fase prototyping dan field tes, telah dinyatakan valid serta realibel berdasarkan dari hasul validasi, uji coba lapangan dan penilaian ahli. Instrumen dinyatakan valid dengan berpacu pada hasil $V a$ yaitu 4,13 dinyatakan valid. Sedangkan reliabilitas dikatan reliabel karena pencapaian tes reliablilitas yaitu 0,69 .

Tabel 3. Hasil Tes Kemampuan Berpikir Tingkat Tinggi

\begin{tabular}{cccc}
\hline Nilai Siswa & Frekuensi & Persentase (\%) & Kategori \\
\hline $80<$ nilai $\leq 100$ & 5 & 21,7 & Sangat baik \\
$60<$ nilai $\leq 80$ & 13 & 56,5 & Baik \\
$40<$ nilai $\leq 60$ & 5 & 21,7 & Cukup \\
$20<$ nilai $\leq 40$ & 0 & 0 & Kurang \\
$0<$ nilai $\leq 20$ & 0 & 0 & Sangat kurang \\
\hline Jumlah & 23 & 100 & \\
\hline Rerata & \multicolumn{3}{c}{69,56} \\
\hline
\end{tabular}

Berdasarkan analisis pengukuran keterampilan berpikir tingkat tinggi peserta didik diperoleh bahwa 23 subjek yang diuji cobakan terdapat 5 peserta didik $(21,7 \%)$ masuk kedalam kategori berpikir tingkat tinggi yang baik, 13 peserta didik (56,5\%) dengan kemampuan berpikir tingkat tinggi baik, 5 peserta didik $(21,7 \%)$ dengan kamampuan cukup, serta nihil dengan kemampuan kurang dan sangat kurang.

Soal akan dinyatakan baik jika sol memiliki tingksat kesulitan berada pada interval 0,31-0,70, dari interval tersebut memperlihatkan soal tersebut tidak terlalu sulit dan tidak terlalu mudah. Hasil dari kerja peserta didik akan mengukur tingkat kesulita tes pada saat uji coba lapangan. Analisis kesukaran tiap soal dalam lampiran. Berikut hasil analisis tes pemecahan permasalahan matematika.

Tabel 4. Analisis Tingkat Kesukaran Instrumen Tes Pemecahan Masalah Matematika

\begin{tabular}{ccc}
\hline No. Soal & Kesukaran & Kategori \\
\hline 1 & 0,82 & Mudah \\
2 & 0,86 & Mudah \\
3 & 0,73 & Mudah \\
4 & 0,77 & Mudah \\
5 & 0,78 & Mudah \\
6 & 0,6 & Sedang
\end{tabular}




\begin{tabular}{ccl}
7 & 0,65 & Sedang \\
8 & 0,74 & Mudah \\
9 & 0,59 & Sedang \\
10 & 0,78 & Mudah \\
11 & 0,62 & Sedang \\
12 & 0,72 & Mudah \\
13 & 0,51 & Sedang \\
14 & 0,58 & Sedang \\
15 & 0,68 & Sedang \\
\hline
\end{tabular}

Dari tampilan tabel tersebut soal 1, 2, 4, 3, 4, 5, 8 dan 12 mempunyai tingkat kesukaran 'mudah'. Dengan artian banyak peserta didik yang menjawab soal dengan benar. Soal nomor 6, 7, 9, 11, 13, 14 dan 15 dengan kategori 'sedang' dengan artian peserta didk yang menjawab benar dan salah seimbang. Tiap soal masuk ke dalam kategori yang baik sesuai dengan kualitas tes, diketahui soal dengan kesukarannya tidak baik dapat dilihat dari tingkat kesukarannya mudah serta tingkat kesukarannya sulit.

Soal tiap instrumen disebut baik jika butir tes mempunyai daya beda kecil yaitu 0,2. Dari hal tersebut membuktikan bahwa soal harus memiliki pembeda cukup. Berikut hasil daya pembeda tes pemecahan masalah dalam bentuk tabel.

Tabel 5. Analisis Daya Pembeda Instrumen Tes Pemecahan Masalah Matematika

\begin{tabular}{ccc}
\hline No. Soal & Daya Pembeda & Kategori \\
\hline 1 & 0,33 & Cukup \\
2 & 0,33 & Cukup \\
3 & 0,04 & Jelek \\
4 & 0,25 & Cukup \\
5 & 0,33 & Cukup \\
6 & 0,13 & Jelek \\
7 & 0,33 & Cukup \\
8 & 0,54 & Baik \\
9 & 0,75 & Sangat Baik \\
10 & 0,20 & Cukup \\
11 & 0,17 & Jelek \\
12 & 0,13 & Jelek \\
13 & 0,29 & Cukup \\
14 & 0,21 & Cukup \\
15 & 0 & Sangat Jelek \\
\hline
\end{tabular}

Berdasarkan tabel 5 didapatkan bahwa soal nomor 8 mempunyai pembeda yang baik, dengan artian soal tersebut baik untuk melihat peserta dengan kemampuan tinggi dengan kemampuan rendah. Dengan soal nomor 9 memiliki daya pembeda yang sangat baik. Soal 1, 2, 4, 5, 7, 10, 13 dan 14 dengan gaya pembeda yang cukup, sedangkan soal 3, 6, 11, 12 dan 15 dengan daya pembeda yang kurang baik. Berpacu pada kriteria tes, terdapat 5 soal dengan kemampuan berpikir tingkat tinggi yang tidak memenuhi kriteria daya pembeda. 
Berdasarkan analisis tingkat kesulitan instrumen tes yang digunakan dapat mengetahui soal tes yang tidak layak memiliki tingkat kesukaran mudah atau sulit, sehingga menghasilkan final protoptype instrumen yang baik sehingga akan menghasilkan soal yang terdiri dari 15 nomor dangan waktu 2 x 45 menit. Diketahui bahwa peserta didik yang masuk dalam kategori tingkat kemampuan tinggi yaitu 15 orang peserta didik, dengan kategori cukup baik yaitu 5 orang, dan kategori sangat baik yaitu 5 orang, serta tidak ada peserta didik yang mempunyai kemampuan berpikir tingkat tinggi kurang ataupun sangat kurang.

\section{SIMPULAN}

Berdasarkan hasil pembahasan tentang tahapan pengembangan yang telah dilaksanakan, dapat ditarik kesimpulan bahwa dalam proses mengembangkan instrumen tes pemecahan masalah matematika peserta didik melewati tiga tahap yaitu : (1) Tahap preliminary, yaitu tahap pendahuluan pengembangan, tahap ini dilakukan untuk mencari gambaran mengenai instrumen tes pemecahan masalah serta menentukan lokasi penelitian. (2) Tahap self evaluation peneliti melakukan perancangan instrumen tes, analisis peserta didik dan materi. Kurikulum yang digunakan yaitu K13, peserta didik yang menjadi subjek ujicoba yaitu kelas VIII SMP Citra Samata Kab. Gowa (3). Tahap prototyping adalah tahap menguji kevalidan instrumen tes pada 3 expert (validator) terdiri dari seorang guru matematika SMP Citra Samata Samata Kab. Gowa serta 2 dosen jurusan matematika fakultas tarbiyah dan keguruan, dan uji coba one-to-one pada 3 orang peserta didik untuk menjawab soal kemudian mengisi komentar terhadap soal, berdasarkan komentar maka instrumen tes akan dilanjutkan ke tahap small group kepada 6 orang peserta didik. Dari hasil analisis small group, selanjutnya akan dilanjutkan ke fase berikutnya. (4) Tahap field test, adalah uji lapangan di SMP Citra Samata Kab. Gowa Kelas VIII agar bisa mengetahui kemampuan pemecahan masalah matematika peserta didik, tingkat kesukaran, reliabilitas, serta daya beda pada instrumen tes yang sudah dibuat, sedangkan hasil instrumen tes valid dan reliabel. Instrumen yang digunakan masuk ke kategori valid yaitu $V a$ 4,13. Reliabilitas yang didapatkan yaitu 0,69 dengan ketegori tinggi. Berdasarkan kriteria kualitas instrumen tes diketahui bahwa terdapat 10 soal mempunyai daya pembeda yang memenuhi kriteria sedangkan 5 soal tidak memenuhi daya pembeda.

\section{DAFTAR PUSTAKA}

Afirda, Y. R., Sa'o, S., \& Dhiki, Y. Y. (2020). Penerapan taksonomi Bloom dalam kemampuan berpikir menyelesaikan soal geometri pada siswa kelas VIII. JUPIKA:Jurnal Pendidikan Matematika Universitas Flores, 3(2), 121-130.

Effendi, R. (2017). Konsep revisi taksonomi Bloom dan implementasinya pada pelajaran matematika SMP. Jurnal Ilmiah Pendidikan Matematika, 2(1), 98-117.

Erniyanti, Junus, M., \& Syam, M. (2020). Analisis ranah kognitif soal latihan berdasarkan taksonomi Bloom revisi pada buku fisika kelas X (studi pada buku karya Ni Ketut Lasmi). Jurnal Literasi Pendidikan Fisika, 1(2), 115-123. https://doi.org/https://doi.org/10.30872/jlpf.v1i2.337 
Faisal, R. (2015). Pengembangan paket tes kemampuan berpikir tingkat tinggi (higher order thinking skill) berdasarkan taksonomi Bloom pada materi matematika kelas VII $S M P$. Universitas Jember, Jember.

Gunawan, I., \& Palupi, A. R. (2016). Taksonomi Bloom-revisi ranah kognitif: kerangka landasan untuk pembelajaran, pengajaran, dan penilaian. Premiere Educandum: Jurnal Pendidikan Dasar dan Pembelajaran, 2(2).

Hamdi, S., Suganda, I. A., \& Hayati, N. (2018). Developing Higher Order Thinking Skill (HOTS) tes instrument using lombok local cultures as contexts for junior secondary school mathematics. REiD (Research and Evaluation in Education), 4(2), 126-135.

Kurniawan, R. Y., \& Lestari, D. (2019). The development assessment instrumens of higher order thinking skills on economic subject. Department of Economic Education, Faculty of Economics, Universitas Negeri Semarang, and ASPROPENDO, APRODIKSI \& ASPAPI, 14(1). https://doi.org/https://doi.org/10.15294/dp.v14i1.19226

Ndiung, S., \& Mariana Jediut. (2020). Pengembangan instrumen tes hasil belajar matematika peserta didik sekolah dasar berorientasi pada berpikir tingkat tinggi. Premiere Educandum: Jurnal Pendidikan Dasar dan Pembelajaran, 10(1), 94-111. https://doi.org/10.25273/pe.v10i1.6274

Netriwati. (2018). Penerapan taksonomi Bloom revisi untuk meningkatkan kemampuan pemahaman konsep matematis. Desimal: Jurnal Matematika, 1(3), 347-352. Retrieved from http://ejournal.radenintan.ac.id/index.php/desimal/index

Nur, F. (2017). Pengembangan bahan ajar matematika kelas VII SMP berdasarkan model pembelajaran Kolb-Knisley berbantuan geogebra sebagai upaya meningkatkan higher-order thinking skill dan apresiasi siswa terhadap matematika. MaPan: Jurnal Matematika dan Pembelajaran, 5(1), 96-109.

Nurfillaili, U., Yusuf, T. M., \& Anggereni, S. (2016). Pengembangan instrumen tes hasil belajar kognitif mata pelajaran fisika pada pokok bahasan usaha dan energi SMA Negeri Khusus Jeneponto Kelas XI Semester I. Jurnal Pendidikan Fisika, 4(2), 83-87. Retrieved from http://journal.uin-alauddin.ac.id/indeks.php/PendidikanFisika

Okta, T. A. (2020). Pengembangan soal-soal sistem persamaan linear satu variabel berbasis higher order thinking skills pada siswa kelas VII SMP Negeri 3 Bajo Kab. Luwu. Institut Agama Islam Negeri (IAIN) Palopo.

Saraswati, I. G. A. A., Suharta, I. G. P., \& Pujawan, I. G. N. (2020). Peningkatan kemampuan berpikir kreatif matematika siswa melalui penerapan model pembelajaran kooperatif dengan strategi aptitude treatment interaction. Jurnal Pendidikan Matematika Undiksha, 11(2), 36-41.

Setiadi, H. (2016). Pelaksanaan penilaian pada kurikulum 2013. Jurnal Penelitian Dan Evaluasi Pendidikan, 20(2), 166-178. Retrieved from http://journal.uny.ac.id/index.php/jpep

Sridadi, \& Utama, A. B. (2016). Pengembangan instrumen tes keterampilan dasar bolatangan bagi mahasiswa. Jurnal Pendidikan Jasmani Indonesia, 12(2), 110-116. https://doi.org/https://doi.org/10.21831/jpji.v12i2.17110

Subagia, I. W., \& Wiratma, I. G. L. (2016). Profil penilaian hasil belajar siswa berdasarkan kurikulum 2013. Jurnal Pendidikan Indonesia, 5(1), 39-54. 